\title{
Occupational therapy intervention into Osteo-Arthritis of the Carpometacarpal joint of the thumb in the South African context
}

\author{
*Robyn Teuchert, B OT (US) \\ Occupational Therapist: Division of Occupational Therapy, Department of Interdisciplinary Health Sciences, Stellenbosch \\ University
}

\author{
*Hester Cecilia Nieuwoudt, B OT (US) \\ * Manja Otero, B OT (US) \\ *Nicola van Zyl, B OT (US) \\ * Marianne Coetzé, B OT (US)
}

Susan de Klerk, B OT (US), DHT (UP), M OT (US)

Lecturer, Division of Occupational Therapy, Department of Interdisciplinary Health Sciences, Stellenbosch University

*These therapists were Stellenbosch University final year students at the time the study was conducted.

Introduction: The carpometacarpal joint (CMCJ) plays a pivotal role in thumb range of motion and positioning and thus essentially, hand function. This study investigated the intervention approach that was preferred in occupational therapy for osteoarthritis (OA) of the $C M C J$ as well as the factors that affect the course of intervention in the South African context.

Methodology: A descriptive qualitative research design was implemented with a purposive sample of occupational therapists in the Western Cape. Data was gathered using semi-structured interviews which were transcribed and analysed.

Findings: Participants interviewed in this study did not follow a fixed intervention regime. The four themes that emerged were: The content of the occupational therapy referral, aspects concerning the patient, assessment practices and intervention practices. Findings demonstrated that it would not be practical to set up a rigid regime, due to the diverse presentation of OA of the CMCJ of the thumb as well as the contributing factors participants reported to impact on course of intervention.

Conclusion: The focus of occupational therapy should be on treating the symptoms of OA of the CMCJ in addition to occupational performance. The compilation of basic guidelines is proposed to provide meaningful intervention within the South African context.

Key words: Carpometacarpal joint, thumb, osteoarthritis, occupational therapy intervention, guideline

\section{INTRODUCTION}

Hand osteoarthritis (OA) is a prevalent condition with a debilitating impact. Kwok et al', reported the prevalence of erosive hand osteoarthritis to be $2.8 \%$ in the general population and $10.2 \%$ in individuals with symptomatic hand osteoarthritis'. They concluded it to have a profound impact on pain and disability in individuals over the age of 55 years'. Although it is difficult to predict future prevalence of this disease it is estimated that OA will be the leading cause of disability by the year $2020^{2}$. As the condition is irreversible, the prevalence increases with age ${ }^{2}$.

The carpometacarpal joint (CMCJ) of the thumb is the second most affected joint by osteoarthritis ${ }^{3}$. Typical symptoms can include pain in the joint, as well as morning stiffness or stiffness due to inactivity ${ }^{4}$. Hand function is therefore often adversely affected in patients with $\mathrm{OA}$ of the $\mathrm{CMCJ}^{4}$. It is postulated that intervention for $\mathrm{OA}$ of the $\mathrm{CMC}$ ) of the thumb should include members of the multidisciplinary team and encompass all factors affected and associated with this condition ${ }^{5}$. Occupational therapy is focused on treating the symptoms associated with this degenerative disease, as well as the impact it has on the client's occupational performance ${ }^{5}$.

Due to the degenerative nature of $O A$, medical intervention centres primarily on symptomatic relief, maintaining function and the prevention of deformities. Occupational therapist's direct specific intervention which contributes toward pain relief, maintaining joint range of motion, preventing deformities and assisting in improving the ability to execute activities of daily living, thus contributing to an overall improvement in the client's quality of life. Limited knowledge exists about the intervention preferred by occupational therapists treating $\mathrm{OA}$ of the $\mathrm{CMC}$ J of the thumb within the South African context. This study therefore aimed to obtain clarity concerning the preferred occupational therapy regimen used by occupational therapists in guiding their intervention of this condition. The factors influencing the course of intervention were also explored.

It is proposed that guidelines for the intervention of OA of the $\mathrm{CMCJ}$ of the thumb within the South African context be developed based on the result of this study. Such guidelines could provide a foundation for selecting appropriate intervention methods and modalities allowing for effective patient management.

\section{LITERATURE REVIEW}

The diagnosis of $\mathrm{OA}$ of the CMCJ of the thumb is assisted by radiological findings as well as the physical examination, patient history and the qualitative assessment of the hand by the medical specialist ${ }^{6}$. Radiological classification systems have been published by a number of authors and organisations and in 1987, the classification system by Eaton and Glickel was published to aid in diagnosing and deciding on a course of intervention of $\mathrm{OA}$ of the $\mathrm{CMCJ}^{7}$. This classification system comprises four stages based on radiological findings ${ }^{7}$. Stage I implies less severity with normal articular contours of the joint while Stage IV indicates the most severe disease with complete deterioration of the joint including sclerotic and cystic 
changes ${ }^{7}$. Eaton and Glickel's classification was reviewed by Berger et al, for intra - and inter- observer reliability ${ }^{6}$. They concluded that while radiography assisted in diagnosing $\mathrm{OA}$ of the $\mathrm{CMCJ}$, disease severity could not reliably be determined by this classification system ${ }^{6}$. Further diagnostic systems proposed by the European League Against Rheumatism (EULAR) and the American College of Rheumatology (ACR) therefore include radiographical findings as part of the diagnosis only ${ }^{4,8}$.

The clinical presentation of OA of CMCJ is variable. The ACR classification criteria has been developed for clinical research studies and is useful in differentiating OA from other inflammatory arthritides $^{8}$. The key features they highlighted included worsening joint pain with activity, morning stiffness lasting less than 30 minutes, stiffness after periods of immobility as well as impairment of function ${ }^{8}$. The major risk factors for hand OA as indicated by EULAR are: individuals over the age of 40 , gender (higher prevalence amongst females), genetic factors, occupation and obesity ${ }^{4}$. The EULAR in 2009 proposed ten criteria for the diagnosis of hand osteoarthritis which were derived through a Delphi consensus method ${ }^{4}$. The main aim of the EULAR recommendation was to provide a method for diagnosis and not only a classification of OA of the CMCJ. The ten criteria include risk factors, typical symptoms, radiographic changes, laboratory tests and the effect of the condition on functioning ${ }^{4}$. It is clear therefore that a similar range of factors should be considered when deciding on a course of intervention for OA of the CMCJ.

Conservative intervention is indicated as a first approach for $O A$ of the $\mathrm{CMCJ}$ and comprises a range of assessment and intervention options which are fully outlined in the occupational therapy literature and usually comprises splinting, the application of joint protection principles and strengthening of the thenar eminence as well as the hand and wrist musculature ${ }^{9-12}$. The literature indicates however that the Eaton and Glickel's classification of OA of the CMCJ, is still used in practice today despite a lack of inter - and intra-observer reliability. It is imperative however that in addition to the stage of OA of the CMCJ that this classification provides; factors such as functional ability, occupational performance deficits and pain should be considered when deciding on a course of intervention particularly in occupational therapy where the effect of the condition on function must be considered.

Evidence-based research on conservative intervention for $\mathrm{OA}$ of the CMCJ was completed by Valdes and Marik in 2010'. They initially identified 204 studies in their systematic review related to the intervention for OA of the CMCJ of the thumb but only 21 studies met the criteria for conservative intervention of $O A$ of the hand ${ }^{9}$. Based on these studies Valdes and Marik concluded that joint protection principles, assistive devices and the application of heat is supported in the literature as valuable in the conservative intervention of $\mathrm{OA}$ of the $\mathrm{CMCJ}^{9}$. Further evidence for the use of a conservative approach was provided by Kjeken, Smedslund and Rikke in their systematic review in $201^{10}$. They determined the effectiveness of splinting and an exercise regimen in the reduction of symptoms of OA of the CMCJ of the thumb. They reported that there was sufficient evidence for the use of splinting as an intervention, but that there was limited evidence for muscle strengthening ${ }^{10}$.

Ye et al. ${ }^{12}$ completed a systematic review to determine the effectiveness of occupational therapy in the conservative intervention of OA of the CMCJ of the thumb in 20II. The studies reviewed provided evidence for techniques that are used to reduce symptomatology in OA of the CMCJ of the thumb, but none reported on changes and outcomes in occupational performance.

A survey to determine the current practice trends in the conservative intervention of OA of the CMCJ was conducted by O'Brien and $\mathrm{McG}$ aha in $2014^{13}$. They confirmed that therapists commonly use the assessments and interventions mentioned in the literature that demonstrate high levels of evidence, when applying conservative intervention of OA of the $\mathrm{CMCJ}$ of the thumb $\mathrm{b}^{6,13}$. This intervention includes assessing range of motion of the $\mathrm{CMC}$, the metacarpal phalangeal joint (MPC) and the interphalangeal (IP) joint of the thumb as well as range of motion of the wrist; and thumb opposition by means of the Kapandji opposition scale. Assessment of grip and pinch strength as well as provocative tests like the CMCJ grind test and tests for ligament laxity are also suggested ${ }^{\prime 3}$. Furthermore, therapists reported using questionnaires and hand function tests as measures of hand performance ${ }^{13}$. The authors highlighted however, that evidence for intervention sufficiently aligned with the needs of the patient, was not reported and did not necessarily exist ${ }^{13}$. Some of the comments by therapists participating in this study suggested that they often decide on a course of intervention based on what the doctor requests during the referral stage rather than on the occupational performance needs of the patient ${ }^{13}$.

Once the disease process in the CMCJ of the thumb is considered severe, surgical intervention is indicated ${ }^{7}$. A range of surgical procedures are described for OA of the CMCJ of the thumb and Vermeulen et al, identified eight procedures which include volar ligament reconstruction, metacarpal osteotomy, carpometacarpal arthrodesis, joint replacement and trapeziectomy with tendon interposition or ligament reconstruction ${ }^{14}$. They concluded that none of the procedures are superior to any of the others ${ }^{14}$.

Gander et $\mathrm{al}^{15}$. indicated that surgical intervention for OA of the $\mathrm{CMCJ}$ is only indicated when conservative intervention has failed and that the choice of surgical intervention should be based on surgeon experience and expertise, as well as patient factors and needs. One of these factors described by Berggren et al ${ }^{16}$. was the age of the patient. The authors found a significant difference $(p$ $=0.03$ ) between the age of patients that elected to have surgical intervention for OA of the CMCJ. Younger patients in their study (mean age of 59 years) elected to have the surgery whereas the patients with a mean age of 65 years chose to continue with conservative intervention ${ }^{16}$. As conservative intervention usually entails the patient not being able to place high functional demand on the hand, this finding was attributed to the younger patients opting for the more aggressive surgical approach ${ }^{16}$.

It is not known if the evidence for intervention of OA of the CMCJ of the thumb, is followed or applies within the South African context. The intention of the study was to:

* identify the factors that impact on occupational therapy intervention and to

* determine whether there is a preferred intervention practice in occupational therapy for OA of the CMCJ in the South African context.

\section{METHODOLOGY}

A qualitative descriptive design was implemented. Therapists were approached through purposive sampling, selected by predetermined criteria. The criteria dictated that participants were required to be qualified occupational therapists registered with the Health Professions Council of South Africa (HPCSA) with a minimum of two years' experience in the field of hand therapy. Eligible participants were approached from the contact details provided by The South African Society of Hand therapists (SASHT). Twenty-two therapists within the Western Cape (Boland region and Cape Metropole) were approached to participate and seven therapists agreed.

Data were collected through individual semi-structured interviews. A general guide of questions was drawn up to ensure consistency on the part of the interviewers. Pre-and post-interviews were conducted with each of the seven participants. Two researchers were present during each interview. The first interviews were transcribed and content analysis followed. Codes, dictating similar meanings, were assigned to different subcategories to create global categories derived from the content, from which themes emerged.

During the second interview information from the previous interview was checked for accuracy with the participants. Through this process of member checking, the participants were given the opportunity to reflect on the information they had provided during the initial interview. 


\section{ETHICS}

Ethical approval was obtained from Stellenbosch University Health research ethics committee (ethics reference number $\mathrm{NI}$ I/04/I I 7). All participants provided signed informed consent and were treated with respect throughout. Identifying factors regarding the participants and their opinions were kept confidential.

\section{FINDINGS AND DISCUSSION}

The seven participants were found to practice in a variety of settings including government and private practice settings. Patients consulting the therapists ranged across low and high socio-economic backgrounds. The findings from the interviews are presented and discussed below.

\section{Factors that impact on the intervention in occupational therapy}

The themes that emerged as contributing factors impacting on the intervention of $\mathrm{OA}$ of the $\mathrm{CMC}$ J of the thumb, were: the content of the referral to occupational therapy and aspects concerning the patient.

\section{Theme I: Referral to occupational therapy}

The referral is the starting point of occupational therapy intervention for patients with OA of the CMCJ. As highlighted in the literature review the intervention approach used is generally recommended in the referral and can direct the course of intervention, as surgical approaches are indicated once conservative intervention fails ${ }^{9,14}$. According to the participants of this study the intervention approach that is recommended is influenced by the following factors:

\section{Limited frequency of referral}

"Osteoartritis algemeen kry ek uh slegs verwysings van een dokter af..." - (Participant 3).

(Translation: I generally receive referrals for osteoarthritis from one doctor.)

The participants indicated that referrals for conservative intervention of $\mathrm{OA}$ of the $\mathrm{CMC}$, were primarily received from general practitioners, rather than orthopaedic surgeons. Frequency of referrals was indicated as low. Participants from the Boland region saw fewer cases than those situated in the Cape Metropole.

"maar daar is van hulle (the patients) wat hoor van die hande kliniek en sal dan self net hier opdaag" - (Participant 4).

(Translation: of the patients, there are those who hear of the hand clinic and arrive of their own accord.)

Self-referrals from the clients were found to be infrequent with only two participants indicating that they had had clients seeking occupational therapy advice of their own accord.

\section{I.2 Referral source - lack of understanding of occupa- tional therapy interventions}

"Ek dink, ek dink dat ' $n$ mens moet meer verkoop uh... by hom maar al hoe " $n$ mens daar sal bykom is maar met navorsings feite" - (Participant 3).

(Translation: I think, I think that one needs to sell the service more, but the only way to do that is with research facts.)

Participants reported that referrals did not always request any of the management strategies addressed in occupational therapy such as limitations in occupational performance. The participants attributed this to the doctors' limited knowledge of conservative intervention for CMCJ OA. Participant three explained that this could be due to a lack of South African research on the effectiveness or value of occupational therapy for OA of the CMCJ.

\section{I.3 Referrals because of good multi-disciplinary team relations}

"omdat ek 'n goeie verhouding het, het sal hulle sommer as ek op die telefoon praat sal hulle sê jy weet mos wat is die beste so besluit jy" - (Participant 2).
(Translation: because I have a good relationship with them, they will inform me telephonically that I must decide what is best.)

Participants valued building a relationship of mutual trust and respect with the referring doctors as a significant factor influencing frequency and nature of referrals. Furthermore, it was identified that the referring doctor's relationship with the therapist and knowledge of effectiveness of occupational therapy, contributed toward determining the information which was relayed to the patient when making decisions regarding intervention options. The participants who indicated that they had built a good relationship with the referring doctors felt that they were more likely to have a higher referral rate for conservative management of OA of the CMCJ than those who did not. It was felt that marketing the role of the occupational therapist contributed towards an increased referral rate.

Referrals for occupational therapy intervention in OA of the $\mathrm{CMCJ}$ of the thumb were found to be infrequent and limited. The participants of the study indicated that this may not only be due to limited knowledge on the part of the doctor and patient. A contributing factor was that some patients chose more aggressive approaches, as highlighted in the study by Berggren et $\mathrm{al}^{16}$.

Collaboration between members of the multi-disciplinary team is essential to ensure success in patient intervention, as highlighted in two studies by Kjeken and colleagues ${ }^{5,10}$. Effective communication and mutual respect between the therapist and doctor is required in order to optimise patient function. This is in relation to their knowledge and opinions regarding intervention options as well as the consideration of the patient's decision. Limited knowledge can be addressed by marketing the evidence related to conservative intervention in an attempt to broaden the knowledge of the scope of services that occupational therapy intervention can provide. This responsibility lies with the occupational therapy profession itself.

\section{Theme 2: Aspects concerning the patient}

Aspects of the patient that influence the course of therapy include: patient level of activity and occupational performance, cost of therapy, patient understanding and knowledge, compliance to therapy, patient motivation as well as presentation of symptoms.

"each person is different, each person has different pain, their movements are different, their function is different so you would adapt your intervention based on that" - (Participant 6).

Participants reported that the patient played the central role in terms of the direction and course of intervention. The degenerative nature of OA results in the necessity for lifelong lifestyle adaptations and changes ${ }^{17}$. Considered factors related to the patient included pain, level of activity, age and the degree to which the CMCJ was affected by $\mathrm{OA}^{9}$.

"finansies wat die hoofrede is hoekom mense nie kan kom vir verdere terapie of vir voorligting nie" - (Participant 3).

(Translation: finances are the main reason why patients can no longer attend further therapy or seek further advice.)

Financial implications were thought to affect intervention. The patient population treated at government institutions could be from low socio-economic circumstances. Participants from government institutions reported that patients often did not arrive for appointments due to difficulties with transport or inability to take leave from work. Lack of resources such as availability of materials, equipment and duration of intervention were also thought to influence the course of intervention. Compliance to therapy was influenced by the patient's inability to attend follow up appointments largely due to the cost of transport and lack of finances in this regard.

Within private practice settings, participants indicated that medical insurance did not always fully cover the costs related to occupational therapy intervention and patients could not always afford to meet these costs themselves. Financial affordability influenced the type of modalities occupational therapists could offer as 
well as the duration of intervention, more specifically with regards to follow up appointments.

Financial aspects are believed to pertain to the South African context. The researchers found no evidence of this impacting the course of intervention in international studies relevant to OA of the CMCJ of thumb.

"baie keer wat die ander probleem is, hulle kry die terapie as ' $n$ surprise, want dis nie 'n deurganse ding wat bekend is oor die algemeen nie" - (Participant 3).

(Translation: often the other problem is that they receive the therapy as a surprise as it is not something which is not generally well-known.)

It was reported that the patients' attitude toward intervention affected success and compliance. This is in accordance the findings from the systematic review by Kjeken et al ${ }^{10}$. In the present study, a patient was considered compliant according to their attendance at follow up appointments. Participants implied that issues concerning compliance could be related to the patient's knowledge regarding the necessity of occupational therapy as well as what the service entails. In other words, the patient's ability to understand the risks and benefits of therapy as well as their ability to comprehend that the full course of intervention would influence the outcome.

"Dit hang van die persoon se aktiwiteite, en sal dan kyk wat die pasient by die huis moet doen, en wat haar motivering is om die spalk te dra, dan sal sy miskien eerder die sagter spalk maak i.p.v lang duim spika" - (Participant 2).

(Translation: it depends on the person's activities, and then we will look at what the patient needs to do at home, and how motivated she is to wear the splint, then I would maybe make the soft splint instead of the long thumb spica.)

Participants reported that no patients presented in the same way and that each patient needed to be treated as individuals and in accordance with the symptoms with which they presented. The diagnostic systems proposed by ACR and EULAR classifications further highlights the need for consideration of factors individual to the patient in determining the course of intervention ${ }^{4,8}$. Participants reflected that due to the clinical presentation being variable, it was difficult to treat every case in the same manner. If inflammation was present, then the participants did not apply heat as a modality for pain relief but if it was not present then heat was used for this purpose. The patient's experience of the condition further affected intervention as each presented with different goals and aspects that were important. The type of splint prescribed was affected by the patient's level of activity, the frequency at which they could wear the splint and the presence of deformities or other complications. This finding is supported by the results of the systematic review by Valdes et al $^{9}$.

\section{B: Preferred intervention practices in occupational} therapy for OA of the CMCJ in the South African context In order to ascertain whether a preferred intervention regimen existed, the researchers considered the occupational therapy process including assessment and treatment practices.

\section{Theme 3: Assessment practices}

"en ook die ander ding is dit regtig belangrik dat jy uh n pyn, 'n tipe pyn evalueering moet doen, want pasiënte vergeet, uhm, dat hulle pyn gehad het voor die tyd" - (Participant 3).

(Translation: and also, the other thing is that it is really important that you... do pain, a type of pain evaluation because the patients forget that they had pain previously.)

Informal assessments were highlighted as one of the main sources of information for occupational therapy intervention planning. The participants indicated that patient interviews were conducted to assess the patients' history in terms of duration of the diagnosis, aspects of pain as well as a basic activity profile. Observations dur- ing functional activities were also used as a measure of assessment relating to range of motion, deformities and position of the hand, hyper-extension of the metacarpal phalangeal joint, inflammation, oedema and stiffness. This finding is however contradictory to the study by O'Brien and McGaha which indicated that therapists use assessment that demonstrate high levels of evidence ${ }^{13}$. Using informal assessments carried out by the therapists in this study were not aligned to the international trends ${ }^{13}$.

"Sal dele van die Smith handfunksie doen, om hulle grepe te bepaal..." - (Participant 2).

(Translation: Will use parts of the smith handfunction, to assess grip.)

As supported by literature, the use of standardised assessments such as the Smith Hand Function Evaluation, the Disability of the Arm Shoulder and Hand Questionnaire (DASH) as well as pain scales was reported ${ }^{13}$. However only parts of the tests were used by some of the participants. Time constraints due to high work load was a factor contributing to the reason why participants did not make use of certain assessments or only used parts of one.

“...en dit maak julle diagnose meer spesifiek dat dit OA is en nie noodwendig al die ander moontlike diagnose wat daar ook is nie so.. ok." - (Participant 4).

(Translation: ... and it makes the diagnosis more specific that it is OA and not necessarily one of the many other possible diagnoses.)

Only two participants made use of a classification system (Eaton and $\mathrm{Glickel}^{4}$ ) to assess the stage of OA of the CMCJ. Other participants indicated that they refer to the $\mathrm{CMC}$ ] as being in either early/ acute stage or late/chronic stage osteoarthritis. This information often came directly from the referring doctor and at times x-rays would accompany the referral letter.

"die grind test, uhm, om te bevestig dat dit OA is" - (Participant 4). (Translation: the grind test to confirm that is it OA.)

The CMCJ Grind test was used by the majority of the participants to assess the integrity of the thumb as well as their experience of pain. O'Brien and McGaha supported the use of the grind test ${ }^{13}$. From the data, it emerged that limited knowledge pertaining to the stages of osteoarthritis in the CMCJ existed. Only two therapists assessed this, with the others not being aware of a classification system nor making use of one. It is important that the diagnosing professional assists in determining the stage of the condition with radiological assessment as well as a clinical examination ${ }^{4,8}$.

\section{Theme 4: Intervention practices}

"in the early stages of $O A$, definitely a nice full comprehension strengthening programme. And what you are looking at strengthening is the counteracting muscles to abductor poll. Adductor poll. So you know that very strong contraction of the thumb and that..., trying to strengthen, or won't strengthen the opposite counteraction muscles who pull back" - (Participant 5).

Intervention was often directed in terms of the progression of $O A$ of the $C M C$ ], in other words whether or not the patient presented with acute or chronic OA. Intervention for the early/ acute stages of osteoarthritis centred primarily on rest. Participants would provide patients with a static splint. No specific splint was preferred by the participants. Pre-fabricated splints were sometimes prescribed in the absence of deformities. However, it was indicated that pre-fabricated splints do not always maintain the correct alignment of the thumb. A home programme for muscle strengthening, joint protection and range of motion exercises was often provided as an accompaniment to the prescribed splint. This aligns with studies by Kjeken et al $^{10}$, Valdes and Marik ${ }^{9}$ as well as Ye et al ${ }^{12}$.

Participants 4 and 5 indicated that with Eaton's stages 3 and 4 the main priority was to maintain independence and prevent further deformities. This was done through custom-made splints and the provision or recommendation of assistive devices. Home programmes were directed towards maintaining joint range with 
minimal muscle strengthening being indicated in stage 3 and no resistive exercises were recommended if the joint was at stage 4.

"dit hang rêrig af van die pasiënt en waarna hulle terug toe moet mik en watter aktiwiteite wil hulle graag wil doen" - (Participant 4).

(Translation: It really depends on the patient and where they aim to return and what activities they would like to do.)

Participants directed their intervention in accordance with the patient's specific occupational performance needs and goals.

Despite the limitations in assessment methods, therapists employed intervention approaches that were supported by literature $e^{9,10,12,13}$. The course of intervention was found to be directed by the details of the referral and the patient-specific aspects. Hence, no fixed regimen for conservative occupational therapy intervention for CMCJ OA was implemented by participants. However, a need for a guideline which considers the various factors emerged.

\section{LIMITATIONS}

Due to time constraints, the researchers were unable to check the accuracy of interpretation of information from the second interview. The researchers applied coding as a group as opposed to co-coding. A further limitation was that investigation of occupational performance areas was not extensively considered.

\section{CONCLUSION}

$\mathrm{OA}$ of the $\mathrm{CMCJ}$ is a client-specific condition, presenting with varying symptoms and therefore no preferred regimen for the intervention of $O A$ in the $C M C$ J of the thumb is required. However, a basic guideline to guide conservative intervention within the South African context was sought by the participants. The focus of occupational therapy should be on treating the symptoms associated with this degenerative disease, but also on factors impacting occupational performance. Conservative intervention for $\mathrm{OA}$ of the $\mathrm{CMC}$ ] is well outlined in the literature and comprises mostly splinting, the application of joint protection principles and strengthening of the thenar musculature and/or the hand and wrist. In addition to the progression of OA of the CMCJ, factors such as functional ability and pain should be considered when deciding on a course of intervention. Conservative intervention as a first approach is indicated and comprises a range of intervention options.

\section{RECOMMENDATIONS}

It is recommended that an evidence-based guideline be established for application within the South African context. The guideline should take into consideration the following variable aspects concerning the patient: symptoms, socio-economic status, attitude towards intervention, knowledge concerning therapy, level of activity and occupational performance needs and goals. The use of standardised tests, applicable within the South African context must be considered. Innovative intervention, approaches toward improved intervention, follow-up and patient compliance must be explored such as electronic follow-up (text or email) and detailed take home information (including but not limited to home programmes) in more than one language in an accessible format. To address the details indicated in the referrals, collaboration and effective communication within the multi-disciplinary team should be a priority. The responsibility lies with the occupational therapists to equip themselves with the necessary knowledge and skills to broaden the intervention requests made in referrals. Future research can address the contribution occupational therapy can make in conservative and surgical intervention approaches within the South African context.

\section{REFERENCES}

I. Kwok WY, Kloppenburg M, Rosendaal FR, van Meurs JB, Hofman A, Bierma-Zeinstra SM. Erosive hand osteoarthritis: its prevalence and clinical impact in the general population and symptomatic hand osteoarthritis. Annals of Rheumatic Diseases. 20I I Jul; 70(7): I2381242.

2. Woolf AD, Pfleger B. Burden of major musculoskeletal conditions. Bulletin of the World Health Organisation. 2003; 8I (9): 646-656.

3. Wilder F, Barrett J, Farina E. Joint-specific prevalence of osteoarthritis of the hand. Osteoarthritis and cartilage. 2006; 14(9): 953-957.

4. Zhang W, Doherty M, Leeb BF, Alekseeva L, Arden NK, Bijlsma JW, et al. EULAR evidence-based recommendations for the diagnosis of hand osteoarthritis: report of a task force of ESCISIT. Annals of Rheumatic Diseases. 2009 Jan; 68(I): 8-I7.

5. Kjeken I, Dagfinrud H, Slatkowsky-Christensen B, Mowinckel P, Uhlig T, Kvien TK, et al. Activity limitations and participation restrictions in women with hand osteoarthritis: patients' descriptions and associations between dimensions of functioning. Annals of Rheumatic Diseases. 2005 Nov; 64(I I): 1633-1638.

6. Berger AJ, Momeni A, Ladd AL. Intra-and Interobserver Reliability of the Eaton Classification for Trapeziometacarpal Arthritis: A Systematic Review. Clinical Orthopaedics and Related Research. 2014; 472(4): II55-II59.

7. Eaton RG, Glickel SZ. Trapeziometacarpal osteoarthritis. Staging as a rationale for treatment. Hand Clinic. I 987 Nov; 3(4): 455-47I.

8. Altman R, Alarcon G, Appelrouth D, Bloch D, Borenstein D, Brandt $\mathrm{K}$, et al. The American College of Rheumatology criteria for the classification and reporting of osteoarthritis of the hand. Arthritis \& Rheumatism. 1990; 33(1I): 1601-1610.

9. Valdes K, Marik T. A systematic review of conservative interventions for osteoarthritis of the hand. Journal of Hand Therapy. 20 I0; 23(4): 334-35I.

10. Kjeken I, Smedslund G, Moe RH, Slatkowsky-Christensen B, Uhlig T, Hagen KB. Systematic review of design and effects of splints and exercise programs in hand osteoarthritis. Arthritis care \& research. 20II; 63(6): 834-848.

I I. Stamm TA, Machold KP, Smolen JS, Fischer S, Redlich K, Graninger $\mathrm{W}$, et al. Joint protection and home hand exercises improve hand function in patients with hand osteoarthritis: a randomized controlled trial. Arthritis Care \& Research. 2002; 47(I): 44-49.

12. Ye L, Kalichman L, Spittle A, Dobson F, Bennell K. Effects of rehabilitative interventions on pain, function and physical impairments in people with hand osteoarthritis: a systematic review. Arthritis Research and Therapy. 201 I; 13(I): R28.

13. O'Brien VH, McGaha JL. Current practice patterns in conservative thumb CMC joint care: Survey results. Journal of Hand Therapy. 2014; 27(I): 14-22.

14. Vermeulen GM, Slijper H, Feitz R, Hovius SE, Moojen TM, Selles RW. Surgical management of primary thumb carpometacarpal osteoarthritis: a systematic review. Journal of Hand Surgery. 201 I; 36(I): 157-169.

15. Gander B, Wollstein R. Surgical Treatment for Thumb CMC Joint Arthritis. Current Rheumatology Reviews. 2013; 9(2): I I3-II8.

16. Berggren, Alva Joost-Davidsson, Jane Lindstrand, Goran Nylander, Bo Povlsen, Magnus. Reduction in the need for operation after conservative treatment of osteoarthritis of the first carpometacarpal joint: a seven year prospective study. Scandinavian journal of plastic and reconstructive surgery and hand surgery. 200 I; 35(4): 4I 5-4I7.

17. Bird H. Arthritis: Your Questions Answered. London: Dorling Kindersley Ltd; 2007.

Corresponding Author

Robyn Teuchert

Email:Robi.teuchert@gmail.com 